\title{
Sulphated glycosaminoglycan synthesis in normal and osteoarthrotic hip cartilage
}

\author{
LAURA S. McKenzie, B. A. HORSBURGH, PETER GHOSH, AND T. K. F. TAYLOR \\ From the Raymond Purves Research Laboratories (University of Sydney), Royal North Shore Hospital of \\ Sydney, St. Leonards, NSW, 2065 Australia
}

SUMmARY The in vitro sulphated glycosaminoglycan metabolism and uronate content of human aged and osteoarthrotic hip articular cartilages have been examined. Cartilages were sampled from nonfibrillated weight-bearing areas and cultured in Dulbecco Modified Eagle's medium with ${ }^{35} \mathrm{SO}_{4}$. Uptake of ${ }^{35} \mathrm{SO}_{4}$ was corrected for total sulphate concentration and related to uronate levels after papain digestion and dialysis. The levels of uronate in these tissues varied between $0.96 \%$ and $2 \cdot 26 \%$ dry weight and did not correlate with either osteoarthrotic grading or sulphated glycosaminoglycan metabolism, irrespective of the source. Glycosaminoglycan metabolism of intact hip articular cartilage from clinically defined osteoarthrotics appears, from these results, to be comparable to that derived from nonsymptomatic hip joints from individuals of similar age. Sodium salicylate was found to depress sulphated glycosaminoglycan metabolism in osteoarthrotic cartilage.

The pathophysiology of osteoarthrosis is now well defined. In the early stages it is characterized by softening of articular cartilage followed by fibrillation and loss of the extracellular proteogylcans (McDevitt, 1973; Mankin, 1974). The hydrated proteoglycans of articular cartilage are responsible for its resilience and self lubricating ability (Maroudas, 1973), and their depletion leads to impaired mechanical function (Kempson et al., 1970, 1973).

The chondrocyte response to depletion of its surrounding matrix has been the subject of investigation for many years. Early autoradiographic studies by Collins and McElligott (1960) showed that chondrocytes in osteoarthrotic cartilage exhibited increased ${ }^{35} \mathrm{SO}_{4}$ uptake. Studies of osteoarthrotic articular cartilage by Mankin and co-workers (Mankin and Lippiello, 1970; Mankin et al., 1971) led these authors to conclude that the synthetic activity of the cartilage cell is increased and it makes some attempt to replace the proteoglycan depleted from the surrounding matrix. Recently, Maroudas (1975) has, however, shown that where articular cartilage is severely fibrillated, ${ }^{35} \mathrm{SO}_{4}$ uptake is less than normal and uptake in mildly fibrillated cartilage appears to be the same as normal.

Accepted for publication October 26, 1976 Correspondence to Dr. P. Ghosh
These findings are in agreement with those of Bollet and Nance (1966) and Lust et al. (1972).

As part of our studies on the effects of antiinflammatory drugs on human cartilage metabolism (McKenzie et al., 1976a), we compared the sulphated glycosaminoglycan metabolism in human aged normal and osteoarthrotic hip cartilages. The results suggest that comparable rates of sulphated glycosaminoglycan synthesis exist in osteoarthrotic and 'normal' cartilage from subjects in the same age range.

\section{Materials and methods}

SOURCE OF ARTICULAR CARTILAGE

Human articular cartilage was obtained from femoral heads removed surgically for osteoarthrosis or after subcapital fracture of the femur. 10 normal and 6 osteoarthrotic femoral heads from donors of known age were studied and classified on the grading system of Collins (1949) according to the severity of osteoarthrotic changes. As far as could be ascertained, patients admitted for fracture of the femur had not taken anti-inflammatory drugs one week before surgery. Osteoarthrotics, however, were known to use anti-inflammatory drugs on a regular basis.

For 'normal' femoral heads, cartilage was sampled from the superior surface. Osteoarthrotic femoral heads frequently showed complete erosion of cartilage in this area, and cartilage samples were taken from 
adjacent areas which were free of osteophytes or severe visible fibrillation. Maroudas et al. (1973) found no significant differences in glycosaminoglycan content over the area of the femoral head, suggesting that the area of cartilage sampled is not critical.

\section{CULTURE METHOD}

This procedure has been described in detail elsewhere (McKenzie et al., 1976b). Full depth slices of cartilage $1 \mathrm{~mm}$ thick were maintained in organ culture, and experiments on ${ }^{35} \mathrm{SO}_{4}$ uptake were carried out on the first or second day after cultures were set up when viability is maximal (McKenzie et al., 1976b). The culture medium used was Dulbecco Modified Eagle's minimum essential medium supplemented with $10 \%$ fetal calf serum (Commonwealth Serum Laboratories, Melbourne, Victoria).

INCORPORATION OF ${ }^{35} \mathrm{SO}_{4}$ INTO SULPHATED GLYCOSAMINOGLYCANS

The synthesis of sulphated glycosaminoglycans in 'normal' and osteoarthrotic articular cartilage was estimated by determining the extent of incorporation of ${ }^{35} \mathrm{SO}_{4}$ into these macromolecules over a 6-hour period. The method, which is described in more detail elsewhere (McKenzie et al., 1976b), consisted of the addition of ${ }^{35} \mathrm{SO}_{4}$ (Radiochemical Centre, Amersham, UK) to the medium 24 hours after initiation of the cultures, to a final concentration of $40 \mu \mathrm{Ci} / \mathrm{ml}$. Three cartilage slices were removed at hourly intervals over the 6-hour experimental period. Incubations were terminated by placing cartilage slices in $5 \mathrm{ml}$ ice-cold physiological saline containing nonradioactive sulphate $(1 \mathrm{mg} / \mathrm{ml})$ as a chaser. The saline was changed three times at 10 -minute intervals to remove the majority of unincorporated sulphate from the cartilage. Slices were dehydrated in acetone and alcohol and dried under vacuum at $60^{\circ}$, then dry weight determined. Solubilization of the tissue was achieved by digestion of each slice with $1 \mathrm{ml}$ crystalline papain (Merck, $1.5 \mathrm{mg} / \mathrm{ml}$ ), in $0.1 \mathrm{M}$ acetate buffer $\mathrm{pH} 5 \cdot 6$, containing $0.05 \mathrm{M}$ EDTA, and $0.005 \mathrm{M}$ cysteine. The digests were dialysed overnight against water to remove the remaining unincorporated ${ }^{35} \mathrm{SO}_{4}$. The radioactivity associated with the glycosaminoglycans present in aliquots of the digest was determined by standard liquid scintillation counting techniques using a Triton $\mathrm{X}-100 /$ toluene scintillation mixture. The uronic acid content of the dialysed digests were determined by the method of Bitter and Muir (1962). The extent of incorporation of ${ }^{35} \mathrm{SO}_{4}$ into glycosaminoglycans was expressed as $\mathrm{cpm} / \mu \mathrm{g}$ uronic acid for each tissue slice. Results were analysed statistically as described by McKenzie et al. (1976a).
EFFECT OF SODIUM SALICYLATE ON SULPHATED GLYCOSAMINOGLYCAN SYNTHESIS IN AGED ANФ OSTEOARTHROTIC ARTICULAR HIP CARTILA E़E The effect of varying concentrations of sodiun salicylate on sulphated glycosaminoglycan synthes.s was determined using cartilage from an osteoarthroftc femoral head from a patient aged 35 years. This was compared with results published previousty (McKenzie et al., 1976a) on the effects of sodium salicylate on articular cartilage from 3 'healthy' femoral heads. The concentrations of sodium salicylate studied were $5 \cdot 0,2 \cdot 5$, and $1 \cdot 0 \mathrm{mmol} / 1$, whigh encompasses the serum therapeutic levels reached $5 y$ this substance in man (Domenjoz, 1971).

\section{Results}

RATE OF ${ }^{35} \mathrm{SO}_{4}$ INCOR PORATION INTO SULPHAT GLYCOSAMINOGLYCANS OF NORMAL AND OSTE $\theta-$ ARTHROTIC HIP CARTILAGE IN VITRO

The rate of incorporation of ${ }^{35} \mathrm{SO}_{4}$ into all samps of aged and osteoarthrotic cartilage was measured over a 6-hour period, 24 hours after initial incubatio $\vec{B}$. The ${ }^{35} \mathrm{SO}_{4}$ in the incubation media was calculated ats parts per million of total inorganic sulphate presemt for each experiment. As the measured radioactivity only reflects a proportion of total ${ }^{35} \mathrm{SO}_{4}$ utilized in $_{\text {in }}$ synthesis, a correction factor was used and the raife of $\mathrm{SO}_{4}$ uptake determined from the expression

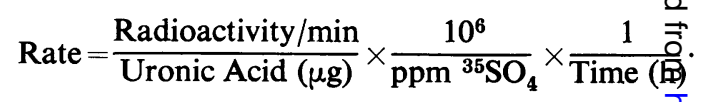

While no allowance was made of the incorporati宊 of ${ }^{35} \mathrm{SO}_{4}$ into keratan sulphate, it was considered on the basis of its low metabolic half life (Maroud \%్ 1975) not to affect our calculations to any great extent.

The results obtained for ${ }^{35} \mathrm{SO}_{4}$ uptake into cartilage from 16 femoral heads, together with uronic acid content, age, classification, and OA grading aspe shown in the Table. As the Table shows there is measurable difference between the rate of ${ }^{35} \mathrm{SQ}_{4}$ uptake into hip articular cartilage classified $\overline{\bar{A}}$ normal or osteoarthrotic grades I-III. The to:AI uronic acid content varied between $0.96 \%$ and $2.26 \%$ on a dry weight basis. There was no obserf able correlation between uronic acid level and rate of ${ }^{35} \mathrm{SO}_{4}$ uptake whether 'normal' grade 0 , šr grades I-III. The effect of sodium salicylate over the concentration range $1 \cdot 0-5.0 \mathrm{mmol} / 1$ on sulphatêd glycosaminoglycan synthesis in osteoarthrotic cart tilage is shown in the Fig. As was previously reported (McKenzie et al., 1976a), sodium salicylate depressegs the synthesis of these macromolecules in normal aggd articular cartilage, and our results confirm that the is also true for osteoarthrotic cartilage. 
Table Results of ${ }^{35} \mathrm{SO}_{4}$ uptake into cartilage of 16 femoral heads

\begin{tabular}{|c|c|c|c|c|}
\hline Classification & $\begin{array}{l}\text { OA Grading } \\
\text { (Collins, 1949) }\end{array}$ & $\begin{array}{l}\text { Age } \\
\text { (years) }\end{array}$ & $\begin{array}{l}\text { Uronic acid } \\
(\% \text { dry wt })\end{array}$ & $\begin{array}{l}\text { Rate of }{ }^{35 S O} \\
\text { uptake } / \mathrm{min} \\
(\mu \mathrm{g} / \mathrm{h}) \times 10^{-1 *}\end{array}$ \\
\hline $\mathbf{F}$ & 0 & 67 & 2.06 & $11 \cdot 3$ \\
\hline $\mathbf{F}$ & 0 & 78 & 1.94 & $8 \cdot 5$ \\
\hline $\mathbf{F}$ & I & 63 & $1 \cdot 60$ & $1 \cdot 5$ \\
\hline $\mathbf{F}$ & I & 70 & $1 \cdot 75$ & $3 \cdot 6$ \\
\hline $\mathbf{F}$ & I & 70 & 1.82 & $1 \cdot 1$ \\
\hline $\mathbf{F}$ & I & 71 & $1 \cdot 33$ & $11 \cdot 1$ \\
\hline OA & I & 78 & 1.99 & $3 \cdot 9$ \\
\hline $\mathbf{F}$ & I & 79 & $1 \cdot 92$ & $9 \cdot 8$ \\
\hline $\mathbf{F}$ & I & 83 & $1 \cdot 20$ & $2 \cdot 7$ \\
\hline OA & II & 70 & $1 \cdot 27$ & $1 \cdot 2$ \\
\hline $\mathbf{O A}$ & $\mathbf{I I}_{\mathbf{J}}^{1}$ & 80 & $1 \cdot 52$ & $2 \cdot 2$ \\
\hline $\mathbf{F}$ & II & 84 & $2 \cdot 26$ & $7 \cdot 0$ \\
\hline OA & III & 35 & $2 \cdot 17$ & $12 \cdot 5$ \\
\hline $\mathbf{O A}$ & III & 51 & 0.96 & $12 \cdot 2$ \\
\hline OA & III & 72 & $1 \cdot 40$ & $3 \cdot 8$ \\
\hline $\mathbf{F}$ & III & 84 & $1 \cdot 67$ & $7 \cdot 0$ \\
\hline
\end{tabular}

$\mathbf{F}=$ surgically removed for fracture of neck of femur; $\mathbf{O A}=$ surgically removed due to osteoarthrosis.

* Rate of $35 \mathrm{SO}$, uptake over a 6 -hour period was adjusted for tota 1 sulphate concentration and its distribution in media and cartilage (Maroudas, 1975) according to the expression-

$$
\text { Rate }=\frac{\text { Radioactivity } / \mathrm{min}}{\text { Uronic Acid }(\mu \mathrm{g})} \times \frac{10^{6}}{\text { ppm }^{35 \mathrm{SO}_{4}}} \times \frac{1}{\text { Time (h) }}
$$

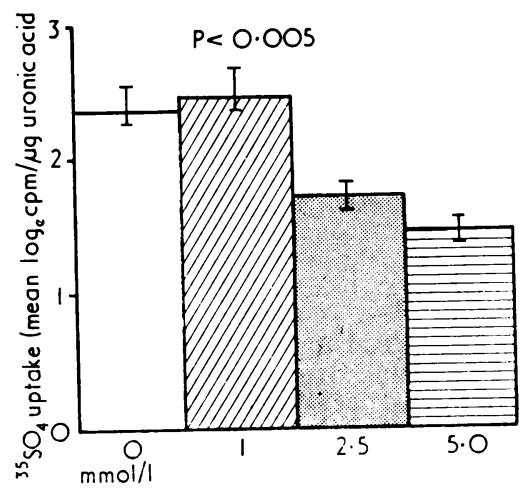

Fig. Effects of sodium salicylate at various concentrations on the uptake of ${ }^{35} \mathrm{SO}_{4}$ into osteoarthrotic cartilage of a femoral head.

\section{Discussion}

Osteoarthrosis is characterized clinically by pain, stiffness, and certain radiological criteria (Sokoloff, 1969). As articular cartilage is aneural, avascular, and alymphatic, pain must arise from the synovium, joint capsule, and other periarticular tissues but the exact mechanisms of pain production are unknown. From the present studies it is apparent that there is no clear relationship between the severity of cartilage damage, assessed by the grading method of Collins (1949), and the appearance of symptoms characteristic of osteoarthrosis, thus, 8 of 9 hips of graded type I and 2 out of 7 graded II-III were derived from patients who came to surgery for fracture of neck of femur and had no previous joint symptoms (Table). The rates of incorporation of ${ }^{35} \mathrm{SO}_{4}$ into glycosaminoglycans were found to be independent of the grading. It should be noted that in all instances visually intact cartilage was sampled and fibrillated areas avoided. This, however, may not be necessary criteria for cartilage integrity, as noted by McDevitt and Muir (1976) who reported that alteration in cartilage glycosaminoglycans may occur before macroscopical change is apparent. While these findings are in reasonable agreement with the studies of Maroudas (1975), Lust et al. (1972), and Bollet and Nance (1966), they contrast sharply with those of Mankin and co-workers (Mankin and Lippiello, 1970; Mankin et al., 1971; Mankin, 1974) and Mayor and Moskowitz (1974) who consider that ${ }^{35} \mathrm{SO}_{4}$ incorporation and glycosaminoglycan synthesis is increased in osteoarthrotic cartilage relative to normal. Mankin et al. (1971) also reported a direct correlation between the rate of glycosaminoglycan synthesis and the condition of articular cartilage as assessed by a grading method. We were unable to show such a relationship. Several factors emerge as possible explanations for these differences. First, we sampled only 'healthy' looking cartilage, carefully avoiding areas of obvious damage. Chondrocytes within these localized fibrillated areas of osteoarthrotic cartilage may show a greater metabolic activity in response to the lower levels, size, composition, and heterogeneity of surrounding glycosaminoglycans (Bollet and Nance, 1966; Bjelle et al. 1972; Hjertquist and Lemperg, 1972; Hjertquist and Wasteson, 1972; Brandt, 1974; Maroudas and Evans, 1974; Ficat and Maroudas, 1975). Second, the origin of the osteoarthrotic cartilage that was examined. Apart from one specimen from a young male, all of those examined could be considered as aged. It is possible that the metabolism of aged and structurally fatigued osteoarthrotic cartilage (Freeman and Meachim, 1973) varies from cartilages derived from osteoarthritides of other aetiology. Last, we initiated our investigations of ${ }^{35} \mathrm{SO}_{4}$ uptake 24 hours after the excised cartilages had been in culture. Previous studies (McKenzie et al., 1976b) had established that cell viability was optimum at this time, and cell 'shock' had probably subsided (Biggers, 1965). After this 24-hour preincubation period, the medium was replaced by fresh solution containing the ${ }^{35} \mathrm{SO}_{4}$, thereby removing foreign substances such as drugs which may have been 
present within the cartilage during the initial incubation period. Some of the most commonly used anti-inflammatory drugs are known to inhibit proteoglycan synthesis (Whitehouse and Bostrom, 1962; McKenzie et al., 1976a) and the degradation of cartilage proteoglycans by neutral proteases (Perper and Oronsky, 1974; Leiss and Kalbhen, 1976).

In previous studies we have shown that the majority of commonly prescribed anti-inflammatory drugs, including sodium salicylate, depress the synthesis of glycosaminoglycans in aged human cartilage (McKenzie et al., 1976a). The comparable rates of ${ }^{35} \mathrm{SO}_{4}$ incorporation into osteoarthrotic and aged human cartilage suggest that these same antiinflammatory drugs would also depress the synthesis of glycosaminoglycans in osteoarthrotic cartilage. The study on the effects of sodium salicylate on glycosaminoglycan synthesis in osteoarthrotic cartilage reinforces this conviction, and once more questions the place of these substances in the management of osteoarthrosis.

We gratefully acknowledge the assistance of Ms. J. Daley in the preparation of this paper; and the National Health and Medical Research Council, and the Clive and Vera Ramaciotti Foundation for financial support.

\section{References}

Biggers, J. D. (1965). Life history of an organ culture. Cells and Tissues in Culture. Methods, Biology and Physiology, Vol. 2, pp. 240-241. Ed. by E. N. Willmer. Academic Press, London.

Bitter, T., and Muir, H. M. (1962). A modified uronic acid carbazole reaction. Analytical Biochemistry, 4, 330-334.

Bjelle, A. O., Antonopoulos, C. A., Engfeldt, B., and Hjertquist, S.-O. (1972). Fractionation of the glycosaminoglycans of human articular cartilage on Ecteola cellulose in ageing and in osteoarthrosis. Calcified Tissue Research, 8, 237-246.

Bollet, A. J., and Nance, J. L. (1966). Biochemical findings in normal and osteoarthrotic articular cartilage. II. Chondroitin sulfate concentration and chain length, water, and ash content. Journal of Clinical Investigation, 45, 1170-1177.

Brandt, K. D. (1974). Enhanced extractability of articular cartilage proteoglycans in osteoarthrosis. Biochemical Journal, 143, 475-478.

Collins, D. H. (1949). The Pathology of Articular and Spinal Diseases. Arnold, London.

Collins, D. H., and McElligott, T. F. (1960). Sulphate $\left({ }^{35} \mathrm{SO}_{4}\right)$ uptake by chondrocytes in relation to histological changes in osteoarthritic human articular cartilage. Annals of the Rhematic Diseases, 19, 318-322.

Domenjoz, R. (1971). The pharmacology of anti-rheumatic agents. Rhematoid Arthritis: Pathogenic Mechanisms and Consequences in Therapeutics, pp. 513-550. Ed. by W. Muller, H.-G. Harwerth and K. Fehr. Academic Press; London.

Ficat, C., and Maroudas, A. (1975). Cartilage of the patella.
Topographical variation of glycosaminoglycan content normal and fibrillated tissue. Annals of the Rheumatic Diseases, 34, 515-519.

Freeman, M. A. R., and Meachim, G. (1973). Ageing, degeh eration and remodelling of articular cartilage. Adm Articular Cartilage, pp. 287-329. Ed. by M. A. R. Freemao. Pitman Medical, London.

Hjertquist, S.-O., and Lemperg, R. (1972). Identification an concentration of the glycosaminoglycans of hum articular cartilage in relation to age and osteoarthrit鹙 Calcified Tissue Research, 10, 223-237.

Hjertquist, S.-O., and Wasteson, A. (1972). The molecula weight of chondroitin sulphate from articular cartilage Effect of age and of osteoarthritis. Calcified Tissue Researcto 10, 31-37.

Kempson, G. E., Muir, H., Swanson, S. A. V., and Freemaf M. A. R. (1970). Correlation between stiffness and the chemical constituents of cartilage on the human femor head. Biochimica et Biophysica Acta, 215, 70-77.

Kempson, G. E., Muir, H., Pollard, C., and Tuke, M. (1973y The tensile properties of the cartilage of human femore condyles related to the content of collagen and glycos aminoglycans. Biochimica et Biophysica Acta, 297 456-472.

Leiss, O. Von, and Kalbhen, D. A. (1976). Untersuchungeth über den durch leukozytäre enzyme stimulierten abbæ⿱亠 von knorpelgewebe und seine beeinflussung durch antra rheumatische arzneimittel. Arzneimittel-Forschung (Drug Research), 26, 165-169.

Lust, G., Pronsky, W., and Sherman, D. H. (1972). Biachemical and ultrastructural observations in normal arid degenerative canine articular cartilage. American Journo of Veterinary Research, 33, 2429-2440.

McDevitt, C. A. (1973). Biochemistry of articular cartilag nature of proteoglycans and collagen of articular cartilage and their role in ageing and in osteoarthrosis. Annals of t Rheumatic Diseases, 32, 364-378.

McDevitt, C. A., and Muir, H. (1976). Biochemical chang $\overrightarrow{\delta 5}$ in the cartilage of the knee in experimental and natura osteoarthritis in the dog. Journal of Bone and Joint Surger 58B, 94-101.

McKenzie, L. S., Horsburgh, B. A., Ghosh, P., and Taylor; T. K. F. (1976a). Effect of anti-inflammatory drugs on sulphated glycosaminoglycan synthesis in aged human articular cartilage. Annals of the Rheumatic Diseases, 35 487-497.

McKenzie, L. S., Horsburgh, B. A., Ghosh, P., and Taylö T. K. F. (1976b). Organ culture of human articulf cartilage: studies on sulphated glycosaminoglycan syn-

thesis. Tissue Culture (in press).
Mankin, H. J. (1974). The reaction of articular cartilage ${ }^{\circ}$ injury and osteoarthritis. New England Journal of Medicine 291, 1285-1292.

Mankin, H. J., and Lippiello, L. (1970). Biochemical anfe metabolic abnormalities in articular cartilage from osteoarthritic human hips. Journal of Bone and Joint Surgery, 52A, 424-434.

Mankin, H. J., Dorfman, H., Lippiello, L., and Zarins, (1971). Biochemical and metabolic abnormalities in articular cartilage from osteoarthritic human hips. IP Correlation of morphology with biochemical and met品 bolic data. Journal of Bone and Joint Surgery, 53\& 523-537.

Maroudas, A. (1973). Physico-chemical properties of articular cartilage. Adult Articular Cartilage, pp. 131-170. Ed. b M. A. R. Freeman. Pitman Medical, London.

Maroudas, A. (1975). Glycosaminoglycan turn-over if articular cartilage. Philosophical Transactions of the Royat Society of London Series B, 271, 293-313. 
Maroudas, A., and Evans, H. (1974). Sulphate diffusion and incorporation into human articular cartilage. Biochimica et Biophysica Acta, 338, 265-279.

Maroudas, A., Evans, H., and Almeida, L. (1973). Cartilage of the hip joint. Topographical variation of glycosaminoglycan content in normal and fibrillated tissue. Annals of the Rheumatic Diseases, 32, 1-9.

Mayor, M. B., and Moskowitz, R. W. (1974). Metabolic studies in experimentally-induced degenerative joint disease in the rabbit. Journal of Rheumatology, 1, 17-23.
Perper, R. J., and Oronsky, A. L. (1974). Enzyme release from human leukocytes and degradation of cartilage matrix. Arthritis and Rheumatism, 17, 47-55.

Sokoloff, L. (1969). The Biology of Degenerative Joint Disease. University of Chicago Press, Chicago and London.

Whitehouse, M. W., and Bostrom, H. (1962). The effects of some anti-inflammatory (anti-rheumatic) drugs on the metabolism of connective tissue. Biochemical Pharmacology, 11, 1175-1201. 